\title{
IMPLEMENTASI ALGORITMA COLLISION DETECTION PADA GAME SIMULATOR DRIVING CAR
}

\author{
Lui Haekal Fasha ${ }^{1}$, Fauziah ${ }^{2}$, M. Gufroni ${ }^{3}$ \\ Teknik Informatika, Fakultas Teknologi Komunikasi dan Informatika, Universitas Nasional \\ Jalan Sawo Manila, Pasar Minggu, Kota Jakarta Selatan, Daerah Khusus Ibukota Jakarta 12520 \\ Telp ( 021 ) 7806700 Faks. ( 021 ) 7802718 \\ luihaekal26@gmail.com ${ }^{1}$, fauziah@civitas.unas.ac.id ${ }^{2}$, m.guroni@gmail.com³
}

\begin{abstract}
Abstrak
Saat ini banyak sekali game engine yang dapat digunakan untuk merancang dan membuat game salah satunya adalah game engine Unity 3D, Unity 3D merupakan sebuah game Engine yang banyak sekali digunakan. Saat ini untuk perancangan atau pembuatan game tidak hanya personal bahkan beberapa depeloverpun menggunakannnya untuk sebuah produksi game nya. Algoritma Collision Detector adalah sebuah metode pendeteksian ketika dua objek atau lebih yang bertabrakan dan akan menimbulkan sebuah reaksi, metode ini sangat banyak digunakan dalam dunia pembuatan animasi maupun pembuatan game. Penulis menggunakan metode ini untuk perancangan sebuah game Simulasi berkendara, ketika player menabrak sebuah objek obstacle / penghalang yang sudah disusun pada sebuah lintasan agar mendapatkan sebuah reaksi pada salah satu objek yang ditentukan. Dari hasil penelitian ini dapat disimpulkan bahwa Fps yang didapatkan pada game ini mencapai titik terbaik dikisaran 60 Frame Per Second dan titik terburuknya berada dikisaran 24,6 Frame Per Second.
\end{abstract}

Kata Kunci :Untiy 3D, Collision Detector, FPS

\begin{abstract}
Currently, there are so many game engines that can be used to design and create games. One of them is Unity 3D. It is now a game engine widely used not only by a person to design or create games but also by some developers to produce games. Collision Detector Algorithm is a method of detecting reaction produced by a collision between two or more objects. The method is primarily used in the animation and game production. The researcher uses this method to design a driving simulation game, in which a player hitting obstacles that have been stacked on a track will experience reaction from one of the specified obstacles. From the results of this study, it can be concluded that the Fps obtained in this game reaches its best point at around 60 Frame Per Second and its worst point at around 24.6 Frame Per Second.
\end{abstract}

Keywords: Game, Untiy 3D, Collision Detector, FPS

\section{PENDAHULUAN}

Seiring berkembangnya kemajuan teknologi. Game-game menjadi sangat mudah didapatkan melalui internet, game menjadi pilihan utama untuk mengisi waktu senggang atau untuk sekedar melepas ketegangan setelah bekerja.Dalam suatu game, biasanya dikembangkan untuk kalangan remaja bahkan dewasa sekalipun untuk hiburan. Game biasanya dimainkan lebih dari satu pemain dalam waktu yang bersamaan
(Game Online) tetapi juga bisa dimainkan sendiri (Stand Alone Game). Metode collision detection merupakan salah satu metode yang bisa digunakan untuk memeriksa suatu kondisi objek apakah terjadi tubrukan objek atau tidak, ketika terjadi tubrukan objek maka beberapa proses bisa dieksekusi dan menghasilkan kembali berupa informasi yang diketahui oleh pengguna sistem [1][2]

Setiap permainan menerapkan collision detection (deteksi tabrakan), baik itu dalam hal tabrakan antara sprite dengan 
spritemaupun antara sprite dengan peluru dan lain-lain. Proses collision dapat dibagi menjadi dua kategori dasar, yaitu collision detection dan collision response, dengan jarak respon yang telah diaplikasikan secara spesifik. Terdapat banyak sekali jenis dari collision detection itu sendiri [3].

Sekarang ini banyak sekali software software yang dirancang untuk membantu dalam proses pembuatan maupun pengembangan game khususnya pada pembuatan game 3D yang bias adisebut game engine. Dengan bantuan game engine seseorang dapat membuat game sesuai dengan kemauan sendiri. Keuntungan lainnya dari game engine adalah tidak diperlukann yatim dalam pembuatannya dan dana yang besar. Salah satu game engine yang sering digunakan saat ini adalah unity 3D tidak hanya perorangan namun beberapa developer pun menggunakan game engine ini untuk projek game mereka walaupun dengan versi yang berbeda. Pada proses pembuatan game, sebaiknya menggunakan system informasi supaya nantinya game akan berbobot dan akan lebih terspesifik sehingga pada saat pembuatan game tidak melewati tahapan - tahapan yang semestinya. Tahapan itu terdiri dari analisa system kebutuhan, perancangan desain, pengkodean, pengujian dan maintaincenya.

Tujuan penelitian ini adalah merancang sebuah game simulator berkendara berbasis pc dengan software unity3D, dimana sang user/player harus menghindari beberapa obstacle yang ada demi mencapai finish. Game ini juga memberikan kesempatan penulis untuk mengembangkan

kemampuan berkreatifitas ditengah perkembangan dunia game. Penerapan konsep algoritma Collision Detection diharapkan dapat menjadi pemicu reaksi dari NPC (Non Player Character) dan objek penghalangnya.
Dalam menentukan perilaku harus berdasarkan dari nilai probabilitas penghitungan bayesian. Jika nilai probabilitas yang paling tinggi dimiliki oleh kategori smash maka perilaku NPC ( Non Player Character ) akan masuk kategori smash. Tapi jika nilai probabilitas yang paling tinggi dimiliki oleh kategori kick maka perilaku tidak akan memilih perilaku kick, melainkan perilaku akan mengecek sesuai dengan metode collision detection, apakah collider yang dimiliki NPC ( Non Player Character) menyentuh collider player, jika collider NPC ( Non Player Character) terbukti menyentuh collider player, NPC( Non Player Character )akan mengambil keputusan untuk memilih perilaku kick[6].

Unity3D ini akan berjalan maksimal jika spesifikasi laptop atau pc yang di gunakan sesuai, spesifikasi minimal yang dibutuhkan software / game engine ini sebagai berikut : Processor Intel Core i32370M. Microsoft Windows 10 64-Bit. Graphic Card $n$ Vidia Geforce 610M 5.1.1f1. Memory (RAM) 2 GB [5].

Gameini di rancang penulis agar user dapat menyelesaikan permasalahan yang ada, karena games angat mudah di terima di semua kalangan.

\section{METODE PENELITIAN}

A. Kerangka Penelitian

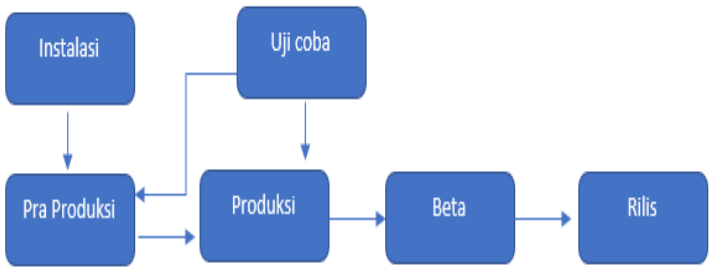

Gambar 1.Tahapan GDLC

Pada gambar 1 merupakan tahapan yang digunakan dalam pembuatan game ini penulis menggunakan metode GDLC 
(Game Development Life Cycle) yang tahapan pertamanya berupa inisiasi yang merupakan perumusan ide dari sebuah game nya, lalu tahapan selanjutnya adalah Pre- Produksi yang merupakan tahapan dari desain game. Setelah Pre Produksi selesai dilakukan masuk ketahap Produksi dimana proses mulai pengkodingan, alur dari sebuah gamenya agar dapat dimainkan. Setelah selesai maka akan masuk ketahap uji coba untuk menemukan buggame dan kekurangan kekurangan lainnya agar diperbaiki. Tahapan akhirnya adalah rilis game yang sudah selesai dibangun melalui tahapan tahapan sebelumnya.

\section{B. Tahapan Perancangan Game}

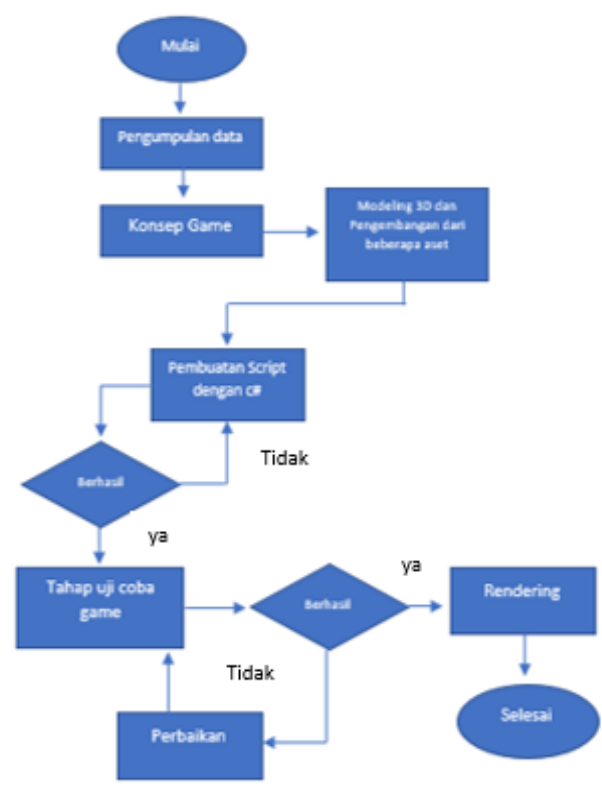

\section{Gambar 2.Flowchart Perancangan Game}

Untuk merancang sebuah game membutuhkan beberapa tahapan yang harus dilaksanakan dengan benar agar nantinya game yang dibuat sesuai dengan rancangan yang ada dan berjalan dengan baik. Dalam pembuatan game simulator driving car ini melalui beberapa tahapan seperti perumusan ide, desain game, pengkodingan, Pembuatan alur perjalan gamenya, tahap uji coba, tahap perbaikan bug, dan rendering game itu sendiri. Gambar 2 merupakan gambaran dari diagram tahapan game yang dibuat untuk menghasilkan gamesimulator driving car.

\section{Algoritma Collision Detector}

Algoritma collision detectionmerupakan proses pengecekan apakahbuah objek spasial salingbertumpuk atau tidak. Jika ternyata adapaling sedikit dua buah objek yangbertumpuk, maka kedua objek tersebutdikatakan saling bertumpukkan. Pada ruangspasial dua dimensi objek yang bertumpukberarti objek spasialnya beririsan. Collision detection merupakan teknik deteksi tabrakan untuk mengetahui objek-objek apa saja yang bersentuhan dalam bidang koordinat tertentu. [2]

Metode ini menggunakan sensor pemicu (triger) untuk mendeteksi keberadaan objek ketika berada di lingkungan virtual. Mekanisme yang mendukung fitur ini adalah area pemicu (sensor) yang ditambahkan di sekeliling mobil. Sensor yang ditambahkan akan dihitung secara matematis untuk menentukan apakah sensor mengenai objek lain seperti tembok (unwalkable object), kendaraan lain, atau objek-objek lain yang berada di lingkungan virtual. [5]

\section{Unity $3 D$}

Unity 3D adalah sebuah game engine yang sangat banyak digunakan saat ini bahkan beberapa developer game juga menggunakan software ini, Unity 3D sudah memiliki menu packages yang cukup lengkap. Penulis menggunakan Untiy 3D untuk medesain latar tempat dan beberapa bagian game lainnya. 


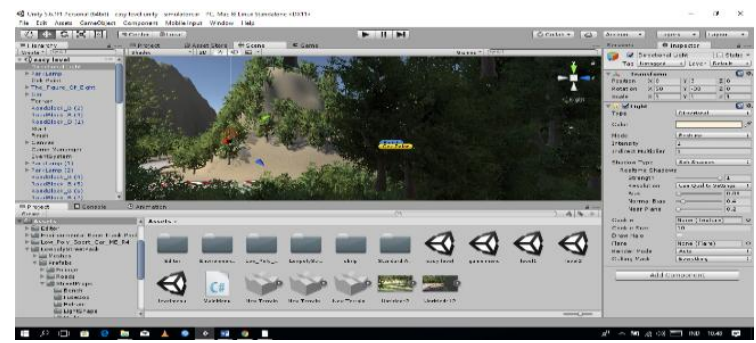

Gambar 3.Software Unity3D

Gambar 3 adalah salah satu contoh tampilan menu packages yang terdapat dalam software unity3D pada proses desain terrain / latar.

\section{E. Adobe Photoshop CC}

Adobe Photoshop merupakan sebuah software desain, kali ini penulis menggunakan software ini untuk membuat desain background menu dan desain menu yang nantinya akan di import kedalam software Unity3D .

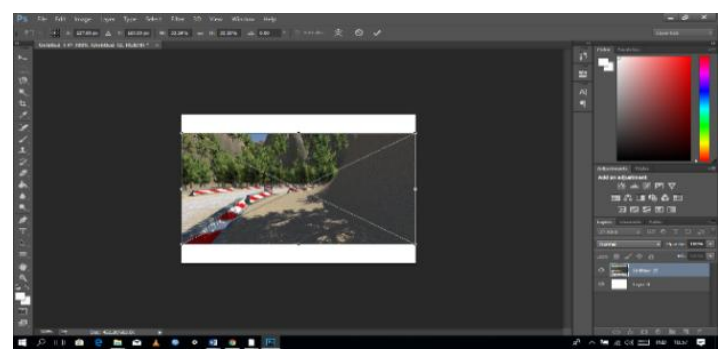

\section{Gambar 4.Software AdobePhotoshopCC}

Pada gambar 4 merupakan tampilan dari software Adobe Photoshop CC yang digunakan dalam tahap desain background untuk tampilan menu pada game.

\section{F. Alur Game}

Game ini dibuat agar user dapat melewati dan menghindari beberapa obstacle / penghalang yang disusun oleh sang creator dan sampai di garis finish, namun untuk melewati obstacle yang ada user harus mengendarai mobil yang disediakan creator dan mengatur kecepatan untuk mencapai garis finish sebelum masuk kedalam scane simulator player akan melewati tahapan seperti flowchart pada gambar 5 .

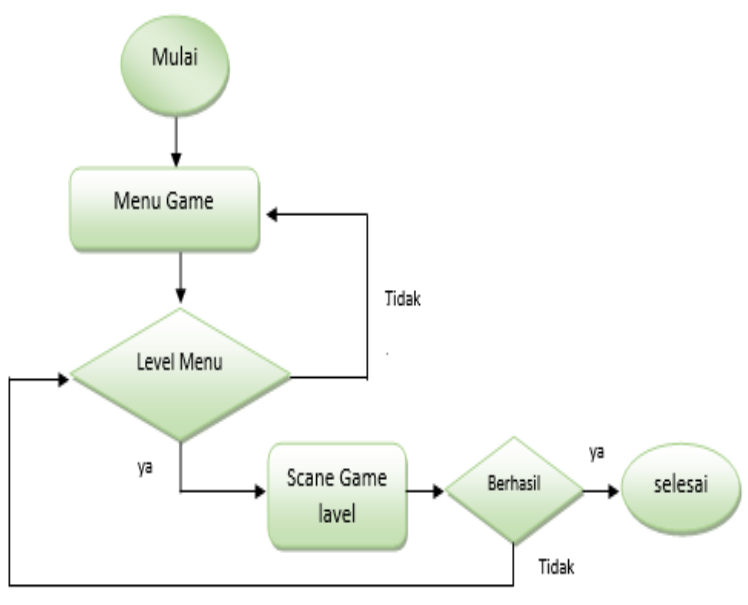

Gambar 5.Flowchart Game

Flowchart pada gambar 5 merupakan alur dari game ini, dimana setelah melewati scene loading player akan masuk ke scene berikutnya yaitu scene menu game yang di dalamnya terdapat 2 button yaitu menu level dan exit. Setelah masuk dalam scene level menu, player akan diberi 3 pilihan level mulai dari easy, medium dan hard saat masuk dalam salah satu scene gamelevel,player diharuskan menyelesaikan test. Ketika berhasil melewati setiap tahapan level maka game ini bisa dikatakan selesai.

\section{HASIL DAN PEMBAHASAN}

\section{A. Desain Menu}

Gambar 4 adalah tampilan menu dari game yang di buat, di dalam tampilan menu awal terdapat 2 button Level and Exit. Button Level adalah button untuk menampilkan pilihan level di tampilan menu berikutnya. Sedangkan buttonExit berfungsi untuk keluar dari game tersebut. 


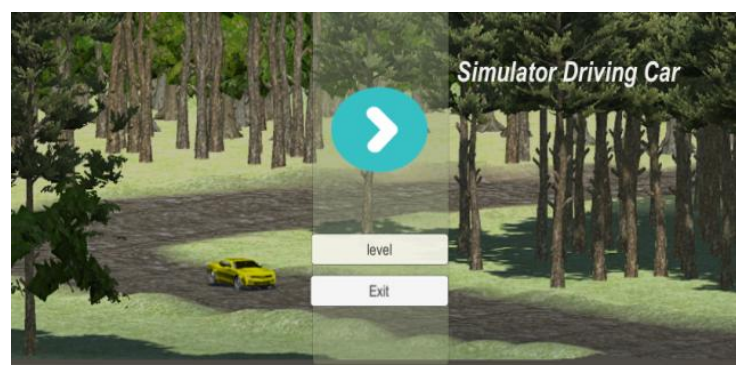

Gambar 6.Tampilan Menu game

Gambar 6 merupakan tampilan dari menu game awal yang di dalamnya terdapat button level dan Exit.

\section{B. Skema Permainan}

Tujuan dari game ini adalah simulasi berkendara, untuk menyelesakan 1 level player diharuskan mencapai finish dengan cara melewati dan menghindari obstacle yang ada padalintasan, jika player menabrak atau mengenai halangan I obstacle yang ada player akan kembali ke start awal dan begitu seterusnya. Untuk levelgame Ada 3 level yang di buat yaitu Easy, Medium, Hard.

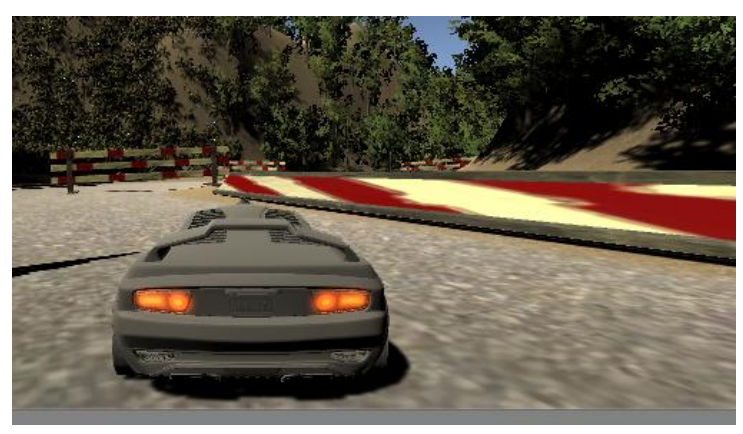

Gambar 7.Tampilan Level Game

Gambar 7 adalah tampilan dari salah satu game level yang terdapat pada game ini.

\section{Pengembangan Asset}

Dalam software unity3D memiliki fitur asset store dimana user dapat mengunduh propertis / asset free maupun tidak, yang dibutuhkan dalam projek game nya. Dalam pembuatan game ini ada beberapa componnet yang digunakan dari asset yang diunduh melalui aset strore yang ada di unity untuk memperindah tampilan dari game ini agar terlihat lebih real.

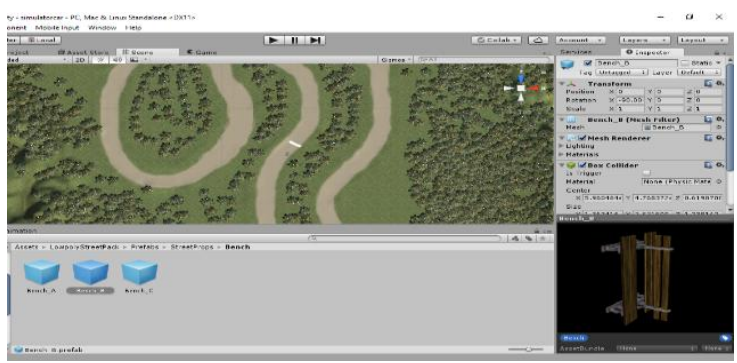

Gambar 8.Objek unduhan Asset Store

Gambar 8 adalah beberapa modeling 3D objek yang saya ambil dari asset store di unity3D untuk melengkapi objek yang dibutuhkan dalam game ini.

\section{Analisis Kebutuhan Perangkat}

Dalam merancang atau membuat game pasti dibutuhkan perangkat - perangkat pendukungnya. Dalam penelitian ini penulis menggunakan beberapa perangkat keras dan perangkat lunak dalam proses perangcangan gamenya, yaitu sebagai berikut :

- Kebutuhan Perangkat Lunak

Tabel 1.Tabel Spesifikasi Perangkat Lunak

\begin{tabular}{c}
\hline NamaPerangkat \\
\hline Unity 3D 5.6.1 \\
Adobe Photoshop cc \\
Mono Develop \\
Windows 10 Home 64-bit \\
\hline
\end{tabular}

Tabel 1 adalah spesifikasi perangkat lunak apa saja yag dibutuhkan dalam game ini mulai dari tahapan desain game bahkan sampai tahap pengkodingan. 
- Kebutuhan Perangkat Keras

Tabel 2. Tabel Spesifikasi Perangkat Keras

\begin{tabular}{ll}
\multicolumn{1}{c}{ Perangkat } & \multicolumn{1}{c}{ Spesifikasi } \\
\hline Prosesor & Intel Core i5 7200U \\
& $2.71 \mathrm{GHz}$ \\
RAM & 4 Gigabyte \\
VGA & 2 Gigabyte \\
\hline
\end{tabular}

Tabel 2 adalah spesifikasi perangkat keras yang dibutuhkan untuk perancangan game Simulator Driving Car ini.

\section{E. Pengujian Fungsional Game}

Uji Fungsional game dilakukan bertujuan agar kita dapat mengetahui apakah game sudah sesuai dengan rancangan yang ada dan jika saat melalui tahap uji coba terdapat beberapa masalah fungsi dapat segera diperbaiki dengan cepat. Dalam Penelitian ini ada 3 tahapan pengujian mulai dari pengujian alur game pada setiap scenenya agar mengetahui alur game berjalan dengan baik dan benar. Tahapan kedua adalah memeriksa grafik frame pada setiap device dengan menggunakan tools mini profiler, Tahapan terakhir pengujian kontrollergame pada setiap fungsi button dan kontrol agar tidak terjadi crash saat dimainkan.

- Pengujian Delay scene Respon

Pengujian delay scene respon dilakukan secara manual dengan menggunakan stopwach untuk mengetahui dellay dari scane 1 ke scene lainnya di setiap perangkat yang berbeda.
Tabel 3 Estimasi Waktu Respon Perangkat

\begin{tabular}{cccc}
\hline Tipe & Processor & RAM & $\begin{array}{c}\text { Estimasi } \\
\text { waktu }\end{array}$ \\
\hline Acer & AMD A8 & 4 GB & 1 Second \\
$\begin{array}{c}\text { E451G } \\
\text { Asus }\end{array}$ & Core i5 & $4 \mathrm{~GB}$ & $\begin{array}{c}0,57 \\
\text { Second }\end{array}$ \\
$\begin{array}{c}\text { A456U } \\
\text { Asus }\end{array}$ & AMD R7 & $4 \mathrm{~GB}$ & 0,35 second \\
X550Z & & & \\
\hline
\end{tabular}

Tabel 3 adalah tabel hasil estimasi respon perangkat untuk pergantian pada setiap scene yang ada dalam game ini.

- Penelitian FPS (Frame Per Second)

Dalam penelitian ini untuk mengukur frame per second penulis menggunakan asset mini profiler yang terdapat dalam asset store, kemudian melihat data yang muncul pada setiap device yang berbeda.

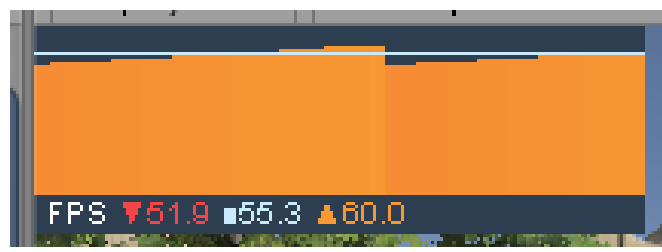

Gambar 8.Tools Mini Profiler

Berdasarkan standar baru yang dibuat oleh ATSC(Advance Television Systems Committee), FPS terbaik yang didapatkan dalam standar video $1080 \mathrm{p}$ berada pada 50 sampai 60 frames persecond.[7]

Tabel 4. Spesifikasi penelitian FPS Device

\begin{tabular}{|c|c|c|c|}
\hline Tipe & Processor & RAM & $\begin{array}{c}\text { Sistem } \\
\text { Operasi }\end{array}$ \\
\hline $\begin{array}{c}\text { Acer } \\
\text { E451G }\end{array}$ & AMD A8 & $4 \mathrm{~Gb}$ & $\begin{array}{c}\text { Windows } 7 \\
64-b i t\end{array}$ \\
\hline $\begin{array}{c}\text { Asus } \\
\text { A456U }\end{array}$ & Core i5 & $4 \mathrm{~Gb}$ & $\begin{array}{l}\text { Windows } 10 \\
\text { Home 64-bit }\end{array}$ \\
\hline $\begin{array}{c}\text { Asus } \\
\text { X550Z }\end{array}$ & AMD R7 & 4GB & $\begin{array}{l}\text { Windows } 10 \\
\text { Home } 64 \text {-bit }\end{array}$ \\
\hline
\end{tabular}


Tabel 4 merupakan tabel spesifikasi perangkat keras yang digunakan dalam pengujian game ini dari sisi Frame Per Secondnya.

Tabel 5. Hasil Percobaan FPS Device

\begin{tabular}{cccc} 
Tipe & $\begin{array}{c}\text { FPS } \\
\text { Terburuk }\end{array}$ & $\begin{array}{c}\text { FPS } \\
\text { Tebaik }\end{array}$ & $\begin{array}{c}\text { Sistem } \\
\text { Operasi }\end{array}$ \\
\hline Acer & 24,6 & 58,7 & $\begin{array}{c}\text { Windows 7 } \\
64-\text { bit }\end{array}$ \\
E451G & & & Windows \\
Asus & 44,3 & 59,4 & $\begin{array}{c}\text { 10 Home } \\
\text { 64-bit }\end{array}$ \\
A456U & & & Windows \\
& & 60,0 & $\begin{array}{c}\text { 10 Home } \\
\text { 64-bit }\end{array}$ \\
Asus & 51,9 & & \\
X550Z & & &
\end{tabular}

Dari Tabel diatas adalah hasil dari tahapan pengujian fungsional Frame Per Second pada setiap perangkat yang tertera.

\section{- Pengujian Algoritma Collision Detection}

Dalam game ini penerapan algoritma Collision Detection terdapat pada dua buah objek agar menghasilkan reaksi untuk kembali ketitik start. Objek yang dipilih adalah NPCnya yaitu mobil sebagai objek utamanya dan Obstacle nya.

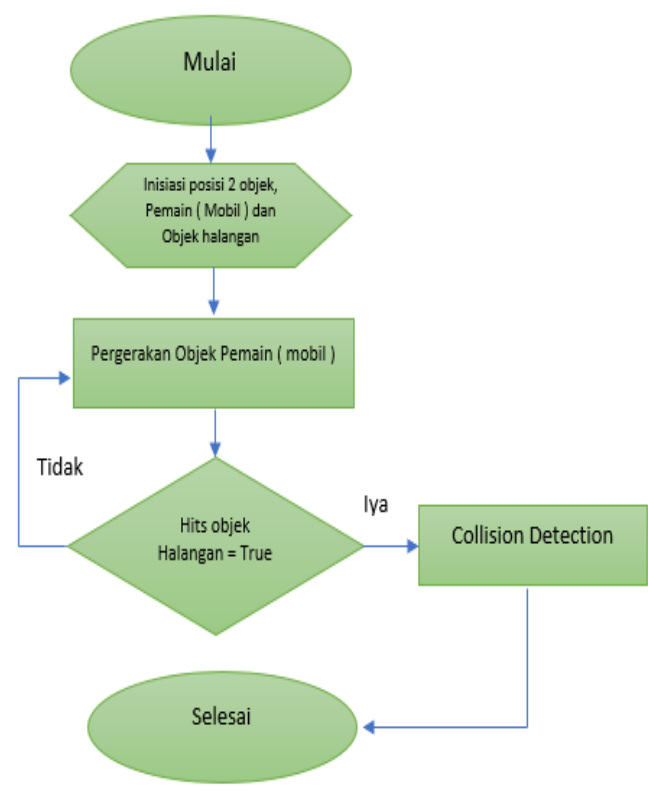

Gambar 8. Flowchart Algoritma Collision Detection
Untuk memastikan algoritma Collision Detection dapat berfungsi dengan baik maka penulis melakukan pengujian dengan Percobaan responsif objek di setiap kordinatnya ketika berbenturan.

\begin{tabular}{|c|c|c|c|c|}
\hline 入 & for & & & \\
\hline Position $X$ & 101.78 & 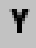 & & Z 228.54 \\
\hline Rotation & -88.48 & $\mathbf{Y}$ & 10.912 & $Z \longdiv { 2 4 8 . 3 6 }$ \\
\hline
\end{tabular}

\section{Gambar 9. Kordinat Objek Di Unity3D}

Untuk mengetahui letak kordinat objek dalam game ini peneliti menggunakan kordinat berdasarkan tools yang di siapkan oleh unity3D dan Gambar 9 merupakan contoh letak salah satu objeknya.

\section{Tabel 6. Hasil Percobaan Responsif Objek}

\begin{tabular}{|c|c|c|c|}
\hline No & Kordinat Objek1(Mobil) & Kordinat Objek 2 ( Road Block) & $\begin{array}{l}\text { Reaksikordinaty yang di } \\
\text { hasillkan }\end{array}$ \\
\hline 1 & $x(246.5), y(0.12), z(328.3)$ & $x(246.5), y(0,12), z(328.3)$ & $x(179,7), y(-0.198), z(317.98)$ \\
\hline 2 & $x(315,2), y(-0,1), z(347,1)$ & $x(315,2), y(-0,1), z(347,1)$ & $x(179,7), y(-0,198), z(317,98)$ \\
\hline 3 & $X(341,3), y(-0,1), Z(296,1)$ & $X(341,3), y(-0.1), z(296,1)$ & $x(179,7), y(-0,198), z(317,98)$ \\
\hline 4 & $x(373.6), y(0.20), z(236.6)$ & $X(373.6), y(0.20), z(236.6)$ & $x(179.7), y(-0.198), z(317.98)$ \\
\hline 5 & $X(345.5), y(0,34), 2(155.7)$ & $X(345.5), y(0,34), 2(155.7)$ & $x(179,7), y(-0,198), 2(317,98)$ \\
\hline 6 & $x(212,6), y(-0,16), z(164,3)$ & $x(212.6), y(-0.16), z(164.3)$ & $x(179,7), y(-0,198), z(317,98)$ \\
\hline 7 & $x(130.9), y(0.11), z(152,6)$ & $X(130.9), y(0.11), z(152.6)$ & $x(179.7), y(-0.198), z(317.98)$ \\
\hline 8 & $x(101.7), y(0.05), z(228.5)$ & $x(101.7), y(0,05), 2(228.5)$ & $x(179,7), y(-0,198), z(317.98)$ \\
\hline
\end{tabular}

Tabel 6 merupakan tabel hasil pengujian responsif objek terhadap algoritma yang diterapkan pada setiap titik letak kordinatnya untuk mengetahui reaksi yang ditimbulkan ketika 2 objek tesebut bebenturan. Pengujian ini dilakukan sebanyak 8 kali pada setiap titik kordinat objek yang berbeda.

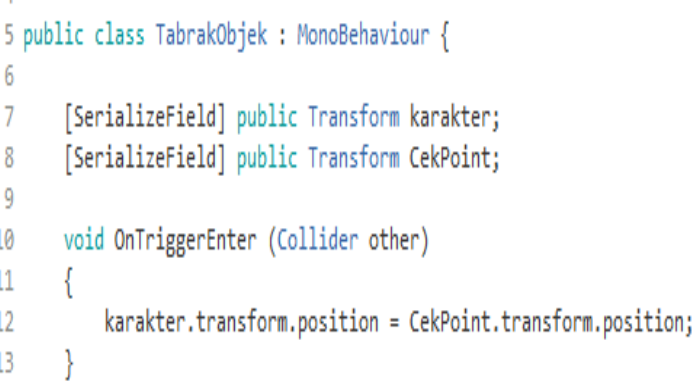

\section{Gambar 10.Script Fungsi Algoritma}


Gambar diatas merupakan potongan script fungsional algoritma Collision Detection yang menghasilkan reaksi kembalinya player ketitik awal ketika menabrak sebuah objek penghalang yang ada pada area lintasan.

\section{SIMPULAN}

Mengacu jurnal - jurnal sebelumnya dan hasil dari penelitian perancangan game simulator driving car dan melalui beberapa tahapan pengujian, Penulis menyimpulkan :

1. Game SimulatorDriving Car sudah dapat berjalan sesuai dengan perancangannya.

2. Penerapan Algoritma Collison Detection pada setiap objek halangan atau obstacle sudah berhasil menimbulkan reaksi, yaitu kembalinya player ke titik start untuk mengulangi tes driving seperti hasil yang dihasilkan pada tabel 6 .

3. Untuk standart yang mengacu pada ATSC(Advance Television Systems Committee), game ini sudah memenuhi standart karena fps yang dihasilkan mencapai titik 60 frame per second.

4. Penerapan fungsional script objek telah berhasil menimbulkan reaksi pada setiap objeknya.

5. Untuk estimasi waktu respons per scane dari awal menu sangat bergantung pada spesifikasi Ram di setiap Devicenya dalam pengujian perangkat keras peneliti menggunakan perangkat dengan spesifikasi 4 GB seperti pada tabel 4 .

\section{DAFTAR PUSTAKA}

[1] Avril, Q. Gouranton, V. \& Arnaldi, B. (2014). Collision Detection: Broad Phase Adaptation From. Journal of Virtual Reality And Broadcasting, Volume N(200n), No. N, 1-14.

[2] Bade, A., Ping, C. S., \& Tanalol, S. H. (2015). Collision Detection For Cloth Simulation Using Bounding Sphere Hierarchy. 1-5.

[3] Bhaskara, S. G., Buana, P. W., \& Purnawan, I. K. (2017). Permainan Edukasi Labirin Dengan Metode Collision Detection Dan Stereoscopic. Lontar Komputer Vol. 8, No. 2, 65-76.

[4] Heidelberger, B., Teschner, M., \& Gross, M. (T.Thn.). Detection Of Collisions And Self-Collisions. 7-8.

[5] Wibawanto, W. (2017). Metode Trigger Detection Untuk Gerakan Kendaraan NPC Dalam Game. Journal of Animation and Games Studies, Vol.3 No.1, 32

[6] Asmiatun, S. (2016). Penerapan Algoritma Collision Detection Dan Bayesian Pada Npc (Non Player Character) Menggunakan Unity 3d. Jurnal Transformatika, Volume 14, 6-11.

[7] ATSC. (2015). "ATSC Standard A/72 Part 1 - VideoSystem Characteristics of AVC in the ATSC DigitalTelevision System".[Online]

Tersedia:https://www.atsc.org/stan dard/a72-parts- 1-2- and-3/.[23 November 2017]. 